Gut, 1968, 9, 411-413

\title{
Blood changes eight years after vagotomy with gastrojejunostomy compared with those after Polya partial gastrectomy
}

\author{
ALAN G. COX, ${ }^{1}$ H. E. HUTCHISON, AND C. A. J. WARDROP \\ From the University Departments of Surgery and Haematology, \\ Western Infirmary, Glasgow
}

There is general agreement that secondary effects on the blood tend to follow surgery for peptic ulcer but most of the available information relates to partial or total gastrectomy. Vagotomy combined with gastrojejunostomy has been widely used in the surgical treatment of chronic duodenal ulcer but few studies have been made of the haematological effects of this procedure (Burge and Pick, 1958; Feggetter and Pringle, 1963; Cox, Bond, Podmore, and Rose, 1964; Hopkinson, 1966). An account is therefore given of changes in the blood eight years after vagotomy combined with gastrojejunostomy and the results are compared with those obtained in a similar series of patients treated by the Polya gastrectomy.

\section{CLINICAL MATERIAL}

The basis of the study was a long-term, prospective investigation started in 1954 in the Peptic Ulcer Clinic at the Western Infirmary, Glasgow. In this project, male patients coming to elective surgery for chronic duodenal ulcer were treated either by the Polya gastrectomy or by total vagotomy with gastrojejunostomy. The choice was made randomly only after the surgeon had completed his preliminary laparotomy and satisfied himself that he could carry out either operation with complete safety.

The present study includes only those patients who had been operated on at least eight years previously. Excluding patients who had died, emigrated, or undergone further gastric surgery, $82 \%$ of the Polya group and $84 \%$ of the vagotomy group were investigated. The two groups of patients were similar in several respects. The mean ages, heights, and weights were almost identical. In the vagotomy group, the mean interval between operation and the present study was 103 months (SD 17.1) which

'Present address: Department of Surgery, Royal Postgraduate Medical School, Ducane Road, London, W.12. does not differ significantly from the corresponding value in the Polya patients (105 months, SD 12.3). Each group is compared with an unselected series of men with unoperated chronic duodenal ulcer who presented for investigation while the present study was in progress.

\section{METHODS}

Haemoglobin, packed cell volume, and mean corpuscular haemoglobin concentration were measured by the methods described by Dacie and Lewis (1963). Serum vitamin $B_{12}$ was estimated by the Euglena gracilis method (Ross, 1952), serum folate by the Lactobacillus casei method (Girdwood, 1960), and serum iron and total iron-binding capacity by the methods of Ramsey $(1953,1957)$.

\section{RESULTS}

The results are presented in two parts. First, a comparison is made between the findings in the patients after the two different operations. Second, the haematological measurements in patients after gastric surgery are compared with those carried out in patients with duodenal ulcer who had not been subjected to operation.

COMPARISON OF THE EFFECTS OF THE TWO OPERATIONS Table I shows mean values in the two groups of patients after operation. Each measurement reveals an advantage for vagotomy with gastrojejunostomy. The differences are generally small but many are statistically significant. The distribution of haemoglobin concentrations is shown in the figure which serves to indicate the actual incidence of abnormal results and confirms the view that the haematological findings after vagotomy with gastrojejunostomy are better.

Seventeen of the gastrectomy patients and four 


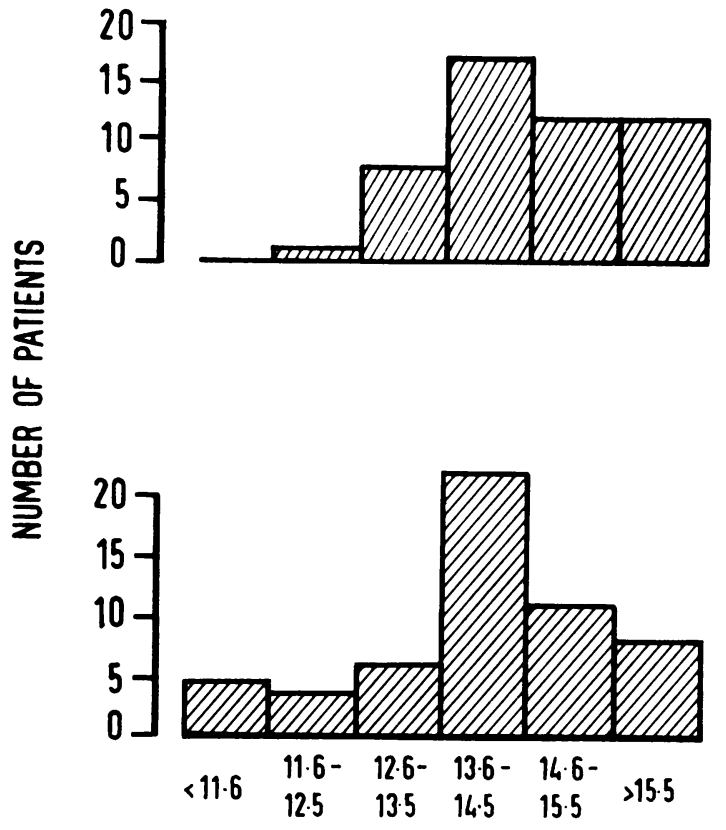

HAEMOGLOBIN g. PER $100 \mathrm{ml}$.

FIG. 1. Distribution of haemoglobin results in vagotomy and gastrojejunostomy patients (above) and Polya gastrectomy patients (below). The height of each column represents the number of patients with results within the range given below. of the vagotomy patients gave a history of oral iron therapy or blood loss during the 12 months preceding the study. Either factor might be expected to influence the state of the blood but exclusion of the findings in these patients does not alter the finding that haematological deficiencies are less after vagotomy than after the Polya gastrectomy. Fifteen of the 17 Polya patients excluded in this way had received prophylactic oral iron therapy and it is reasonable to suppose that some of these patients might otherwise have been significantly anaemic. It is therefore possible that the true extent of iron deficiency after Polya gastrectomy had been masked.

COMPARISON WITH UNOPERATED PATIENTS Table II shows the mean values for haemoglobin, serum iron, total iron-binding capacity (TIBC), and percentage saturation of the latter with iron in unoperated male duodenal ulcer patients and in the two postoperative groups. With the exception of the TIBC in the vagotomy patients, all values in the postoperative patients were significantly lower than in the unoperated patients.

\section{DISCUSSION}

The main purpose of the present study was to make a comparison between two gastric operations for chronic duodenal ulcer. For many years the Polya gastrectomy was used because of its effectiveness in preventing recurrent ulceration. Subsequently its

TABLE I

MAIN RESULTS IN ALL PATIENTS AFTER OPERATION

\begin{tabular}{|c|c|c|c|c|}
\hline \multicolumn{2}{|c|}{ Vagotomy with Gastrojejunostomy } & \multicolumn{2}{|c|}{ Polya Gastrectomy } & \multirow[b]{2}{*}{$P$} \\
\hline No. & Mean $\pm S D$ & No. & $M e a n \pm S D$ & \\
\hline 50 & $14.7 \pm 1.3$ & 54 & $14.0 \pm 1.4$ & $<0.01$ \\
\hline 50 & $43.9 \pm 3.3$ & 54 & $42.5 \pm 3.6$ & $<0.05$ \\
\hline 50 & $33.5 \pm 1.5$ & 54 & $33.0 \pm 1.5$ & N.S.' \\
\hline 49 & $97 \pm 44$ & 55 & $82 \pm 53$ & N.S. ${ }^{1}$ \\
\hline 45 & $352 \pm 60$ & 51 & $378 \pm 76$ & N.S. ${ }^{1}$ \\
\hline 45 & $28.5 \pm 12 \cdot 3$ & 51 & $22.9 \pm 13.1$ & $<0.05$ \\
\hline 47 & $208 \pm 74$ & 51 & $176 \pm 55$ & $<0.02$ \\
\hline 47 & $8 \cdot 3 \pm 3 \cdot 6$ & 50 & $7.7 \pm 3.3$ & N.S. ${ }^{1}$ \\
\hline
\end{tabular}

'Not statistically significant $(P>0.05)$

TABLE II

COMPARISON OF UNOPERATED DUODENAL ULCER PATIENTS WITH THOSE AFTER SURGERY

\begin{tabular}{|c|c|c|c|c|c|c|c|c|}
\hline & \multicolumn{2}{|c|}{ Duodenal Ulcer } & \multicolumn{3}{|c|}{ Vagotomy with Gastrojejunostomy } & \multicolumn{3}{|c|}{ Polya Gastrectomy } \\
\hline & No. & Mean $\pm S D$ & No. & Mean $\pm S D$ & $P^{1}$ & No. & $M e a n \pm S D$ & $P^{\mathbf{1}}$ \\
\hline $\begin{array}{l}\text { Haemoglobin }(\mathrm{g} / 100 \mathrm{ml}) \\
\text { Serum iron }(\mu \mathrm{g} / 100 \mathrm{ml}) \\
\text { TIBC }(\mu \mathrm{g} / 100 \mathrm{ml}) \\
\text { Saturation of TIBC }(\%)\end{array}$ & $\begin{array}{l}63 \\
61 \\
46 \\
46\end{array}$ & $\begin{array}{ll}16 \cdot 1 & \pm 1 \cdot 3 \\
116 & \pm 42 \\
338 & \pm 59 \\
35 \cdot 1 & \pm 12 \cdot 1\end{array}$ & $\begin{array}{l}50 \\
49 \\
45 \\
45\end{array}$ & $\begin{aligned} 14 \cdot 7 & \pm 1 \cdot 3 \\
97 & \pm 44 \\
352 & \pm 60 \\
28 \cdot 5 & \pm 12 \cdot 3\end{aligned}$ & $\begin{array}{l}<0.001 \\
<0.05 \\
\text { N.S. } \\
<0.02\end{array}$ & $\begin{array}{l}54 \\
55 \\
51 \\
51\end{array}$ & $\begin{array}{ll}14 \cdot 0 & \pm 1 \cdot 4 \\
82 & \pm 53 \\
378 & \pm 76 \\
22 \cdot 9 & \pm 13 \cdot 1\end{array}$ & $\begin{array}{l}<0.001 \\
<0.001 \\
<0.01 \\
<0.001\end{array}$ \\
\hline
\end{tabular}

${ }^{1}$ Significance of difference from mean value in duodenal ulcer patients 
popularity waned, partly because of appreciation of a rather high incidence of nutritional deficiencies. The most common of these is anaemia which is usually due to iron deficiency but which is occasionally due to deficiency of either serum vitamin $B_{12}$ or folic acid. Vagotomy is favoured because it obviates the need to remove part of the stomach and this might be expected to reduce the incidence of undesirable metabolic sequelae. Workers who have investigated this problem agree that anaemia is uncommon after vagotomy with gastrojejunostomy (Burge and Pick, 1958; Feggetter and Pringle, 1963; Hopkinson, 1966). However, one previous study has indicated that anaemia is more common after this operation than in a group of normal subjects (Cox et al, 1964).

The present study was possible because of the existence of a unique group of patients who had been randomly allocated to either the Polya gastrectomy or vagotomy with gastrojejunostomy in the middle of the $1950 \mathrm{~s}$. It tends to confirm the belief that vagotomy results in a lower incidence of haematological abnormalities than does the Polya partial gastrectomy. This accords with the findings of Burge and Pick (1958).

However, vagotomy is not entirely free from haematological consequences as is shown by the lower haemoglobin and serum iron values after vagotomy compared with unoperated duodenal ulcer patients. This confirms the finding of an earlier study (Cox et al, 1964) in which some patients as early as four years after vagotomy with gastrojejunostomy also had low haemoglobin and serum iron values.

The most remarkable findings in the series is the low incidence of overt anaemia (see Fig.). This can be attributed in part to the exclusion of women who show a greater susceptibility to iron deficiency after gastric surgery (Hobbs, 1961) and in part to the history of recent oral iron therapy in many of the gastrectomy patients.

\section{SUMMARY}

A haematological study has been carried out in 107 men more than eight years after surgery for chronic duodenal ulcer. The operation was the Polya partial gastrectomy in approximately half the patients and vagotomy with gastrojejunostomy in the remainder. A true comparison of the effects of the two operations was possible because the choice of operation had been made randomly. All haematological measurements show an advantage for vagotomy with gastrojejunostomy but the differences are small.

We gratefully acknowledge the encouragement and advice of Professor A. W. Kay and the ready cooperation of Dr J. F. Adams who carried out the serum vitamin $B_{12}$ estimations.

\section{REFERENCES}

Burge, H., and Pick, E. J. (1958). Long-term results of vagotomy and gasiro-enterostomy in chronic duodenal ulceration. Brit. med. J., 1, 613-615.

Cox, A. G., Bond, M. R., Podmore, D. A., and Rose, D. P. (1964). Aspects of nutrition after vagotomy and gastrojejunostomy. Ibid., 1, 456-469.

Dacie, J. V., and Lewis, S. M. (1963). Practical Haematology, 3rd ed. Churchill, London.

Feggetter, G. Y., and Pringle, R. (1963). The long term results of bilateral vagotomy and gastrojejunostomy for chronic duodenal ulcer. Surg. Gynec. Obstet., 116, 175-179.

Girdwood, R. H. (1960). Microbiological methods of assay in clinical medicine with particular reference to the investigation of deficiency of vitamin $B_{12}$ and folic acid. Scot. med. J., 5, 10-22.

Hobbs, J. R. (1961). Iron deficiency after partial gastrectomy. Gut, 2, 141-149.

Hopkinson, B. R. (1966). A comparison of the results of vagotomy and pyloroplasty with vagotomy and gastro-enterostomy for chronic duodenal ulcer. Brit. J. Surg., 53, 1046-1048.

Ramsey, W. N. M. (1957). The determination of the total iron-binding capacity of serum. Clin. chim. Acta, 2, 221-226.

(1953). The determination of iron in blood plasma or serum. Biochem. J., 53, 227-231.

Ross, G. I. M. (1952). Vitamin $B_{12}$ assay in body fluids using Euglena gracilis. J. clin. Path., 5, 250-256. 